\title{
Trends in Biological Diversity Contents of Science Textbooks from Korea, Indonesia, And The USA
}

\author{
Noviana Astuti Irna Sakir', Jae Geun Kim² \\ ${ }^{1}$ Department of Biology Education, Seoul National University, Seoul 08826, Korea \\ ${ }^{2}$ Center of Education Research, Seoul National University, Seoul 08826, Korea
}

\begin{abstract}
Representative science textbooks for secondary school students from Korea, Indonesia, and the USA were compared to explain the trends of biodiversity images and description among each country's textbooks. For comparison, a specialised technical book was added as a reference book. Textbooks from Korea, Indonesia, and the USA have similar main sub-sections of biodiversity contents. However, both Indonesian and American biological textbooks have special additional sub-sections that differed from Korean textbook. However, none of these biological textbooks presented fully similar explanation with the reference book as a standard. Since there were several differences in explaining major topics of biodiversity in each country, we suggest that curricula compilers adapt provided biodiversity related-contents for presenting them better in the future. In addition, we also suggest biology textbook authors in Korea to add more native biological diversity examples in biodiversity content especially in conservation sub-section. With this, we hope students can learn and know more their countries' biodiversity richness through biological textbook.
\end{abstract}

Keywords: biodiversity, biology textbook, conservation, curriculum, native species, non-native species. 